\title{
Gender Reassignment Surgery in Human Immunodeficiency Virus-Positive Patients: A Report of Two Cases
}

\author{
Seok-Kwun Kim, Ji-An Choi, Myung-Hoon Kim, Min-Su Kim, Keun-Cheol Lee \\ Department of Plastic and Reconstructive Surgery, Dong-A University School of Medicine, Busan, Korea
}

It is believed that surgery on human immunodeficiency virus (HIV)-positive patients is dangerous and should be avoided due to the possibility of postoperative infection of the patients or HIV occupational transmission to the medical staff. We discuss here the preparations and measures needed to conduct surgery safely on HIV-positive patients, based on our experience. We performed sex reassignment surgery on two HIV-positive patients from January 2013 to January 2015. Both of them were receiving highly active antiretroviral therapy and were asymptomatic, with a normal CD4 count ( $>500$ cells $/ \mu \mathrm{L}$ ). The HIV-RNA was undetectable within the bloodstream. All the staff wore protective clothing, glasses, and three pairs of protective gloves in the operating room because of the possibility of transmission. Prophylactic antibiotics were administered to the patients, and antiviral therapy was performed during their perioperative course. Neither of the patients had postoperative complications, and none of the medical staff experienced accidental exposure. Both patients had satisfactory surgery outcomes without complications. HIV-positive patients can undergo surgery safely without increased risk of postoperative complications or HIV transmission to the staff through the proper use of antibiotics, active antiretroviral therapy, and supplemental protective measures with post-exposure prophylaxis for the staff in case of HIV exposure.

Keywords Sex reassignment surgery / HIV infection / Post-exposure prophylaxis
Correspondence: Seok-Kwun Kim Department of Plastic and Reconstructive Surgery, Dong-A University School of Medicine, 26 Daesingongwon-ro, Seo-gu, Busan 49201, Korea

Tel: +82-51-240-5416

Fax: +82-51-243-5416

E-mail:sgkim1@dau.ac.kr

This study was supported by research funds from Dong-A University.

This study was presented at the 4 th Research \& Reconstructive Forum on April 3-4, 2014 in Busan, Korea.

No potential conflict of interest relevant to this article was reported.

Received: 25 Jun $2015 \bullet$ Revised: 4 Aug $2015 \bullet$ Accepted: 7 Sep 2015

pISSN: 2234-6163 • elSSN: 2234-6171 • http://dx.doi.org/10.5999/aps.2015.42.6.776• Arch Plast Surg 2015;42:776-782

\section{INTRODUCTION}

Since the 1980s, 79 million acquired immune deficiency syndrome (AIDS) patients have been reported among those infected with the human immunodeficiency virus (HIV), and 39 million of them have died. Since HIV mortality peaked in 2005, the rate has trended downward due to enhanced accessibility to treatment as well as developments in active antiretroviral therapy (ART) $[1,2]$. With the introduction of highly active antiret- roviral therapy (HAART), the mortality from and the prevalence of HIV infection have significantly decreased. Nevertheless, the number of HIV patients has been reported to be about 35 million as of 2015 , so appropriate treatments must be administered and new developments must be controlled. HIV decreases the number of CD4 T-cells and interferes with the functions of macrophages and monocytes, resulting in the development of symptoms of deficiency in immunity. Whatever the cause may be, immunosuppression clearly increases infection 
risk [3]. Since HAART was introduced in 1996, the mortality of HIV patients has significantly decreased due to the development of treatment regimens. With an increase in the CD4 T-cell number after appropriate HAART treatments, patients' immune functions recover ("immune recovery syndrome"), and consequently, more and more HIV patients are surviving longer than before. Accordingly, the frequency of AIDS-associated complications is increasing $[4,5]$. In this situation, surgical treatment of HIV patients is still not being actively performed due not only to the patient's high infection risks but also to the surgical team's infection risks during the surgery. In this study, safety measures for reducing the risks of HIV transmission to the surgical team and reducing opportunistic infections in gender identity disorder patients who had undergone sex reassignment surgery in the authors' hospital were investigated.

\section{CASES}

Between January 2013 and April 2015, two HIV-positive patients underwent sex reassignment surgery in the Dong-A University hospital. They were male-bodied gender identity disorder patients who wanted to present as female. They were diagnosed as HIV-positive in their preoperative screening test (HIV antibody test) and definitive test (plasma HIV RNA). They received HAART treatments from six months before the surgery using the efavirenz (EFV), tenofovir (TDF), and emtricitabine (FTC) regimen. Then surgery was performed only when the CD4 T-cell count was 500 or more preoperatively after the antiviral treatments, and when the blood viral load was confirmed to be undetectable in the polymerase chain reaction (PCR) test for HIV RNA. After the two patients were admitted to an isolation ward, routine hematology, chemistry, and coagulability laboratory tests were conducted before their operation to exclude any active infection. First-generation cephalosporin (1 g cefazolin IV) prophylactic antibiotics were administered 30 minutes before the surgery. For the preoperative skin preparation, $4 \%$ chlorhexidine gluconate, betadine, and alcohol were used. Disposable and waterproof tissues were used in all the surgical drapes. The entire surgical team wore protective glasses, protective clothes on top of their scrub suits, and three pairs of surgical gloves. In case of occupational exposure of the surgical team during the surgery, the post-exposure prophylaxis (PEP) procedure recommended by the New York State Department of Health AIDS Institute would have been implemented. The patients underwent first-generation cephalosporin antibiotic (1 g cefazolin) therapy for three days even before their surgery, and for one month postoperatively, and the CD4 T-cell count test was conducted to evaluate their immunostatus. After the surgery, the patients were closely monitored for the development of any complication such as infection, delayed wound healing, and progression of the HIV disease state. After the patients were discharged, they underwent regular follow-up as outpatients to closely monitor any development of complications (Table 1).

\section{Case 1}

A 38-year-old HIV-positive male-bodied patient who had a female gender identity underwent HAART for six months preoperatively. The patient was then confirmed by a preoperative CD4 T-cell count test to have had a 925 cells $/ \mu \mathrm{L}$ count, which was a 500 or higher CD4 T-cell count (Stage 1). The result of the PCR test on HIV RNA was confirmed to be 'undetectable, so the surgery was performed as planned. Thanks to the thorough protection using various types of equipment, the surgical team did not experience accidental exposure such as percutaneous needle stick or cutting injury. The patient showed a favorable course without experiencing complications such as postoperative wound infection or delayed wound recovery. The CD4 T-cell count test conducted one month postoperatively confirmed a 971 cells $/ \mu \mathrm{L}$ (Stage 1) count, and no patient deterioration or HIV disease progress was observed. The vagina reconstruction was successful. During the 10-month follow-up after the surgery, no specific complications developed, and a favorable course was maintained (Fig. 1).

\section{Case 2}

The 50-year-old HIV-positive male-bodied patient had undergone penoscrotal vaginoplasty 20 years earlier. He visited the authors' hospital for reconstruction due to vaginal contracture. After HAART was performed for six months preoperatively, a CD4 T-cell count test was conducted, and the result was 778

\section{Table 1. Patient demographics}

\begin{tabular}{|lcccccc}
\hline Patient & Age (yr) & Sex & Operation & $\begin{array}{c}\text { Preoperative CD4 } \\
\text { count (cells/uL) }\end{array}$ & $\begin{array}{c}\text { PCR testing for } \\
\text { HIV RNA }\end{array}$ & $\begin{array}{c}\text { Length of follow-up } \\
\text { (mo) }\end{array}$ \\
\hline 1 & 38 & Male $\rightarrow$ female & Penoscrotal vaginoplasty & 925 & Undetectable \\
2 & 50 & Male $\rightarrow$ female & Vaginoplasty by FTSG & 778 & Undetectable \\
\hline PCR, polymerase chain reaction; HIV, human immunodeficiency virus; FTSG, full thickness skin graft. & 7 & \\
\hline
\end{tabular}




\section{Fig. 1. Case 1: Penoscrotal vaginoplasty}

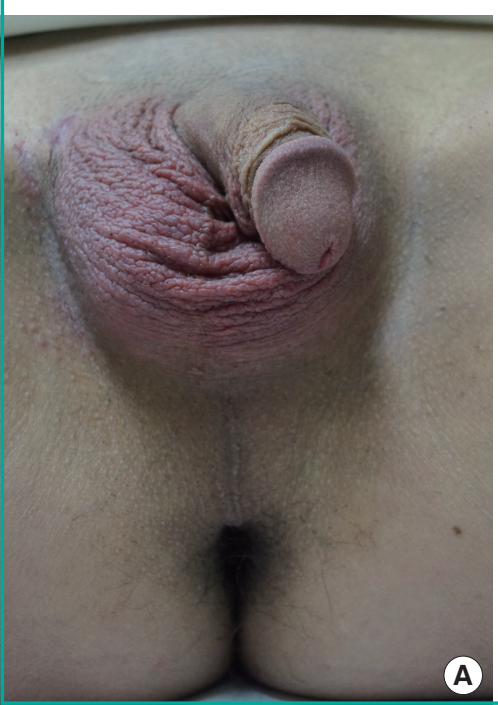

(A) Preoperative image. (B) Image 10 months postoperatively: penoscrotal vaginoplasty had been performed. (C) Inner image of the reconstructed vagina 10 months after the surgery: the flap was well-engrafted, and the width and depth of the vagina were appropriate.

A
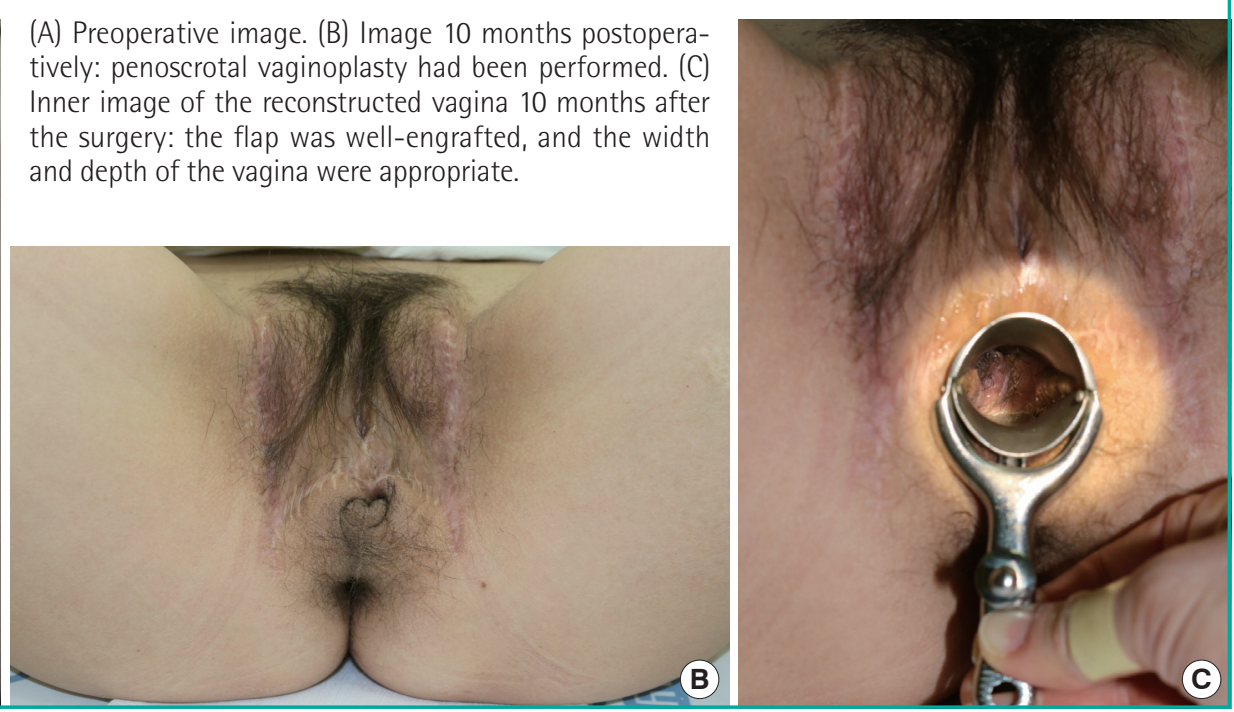

Table 2. Postoperative complications

\begin{tabular}{|lcccccc}
\hline Patient & Age (yr) & Operation & Follow-up (mo) & $\begin{array}{c}\text { Postoperative } \\
\text { infection }\end{array}$ & $\begin{array}{c}\text { Delayed wound } \\
\text { healing }\end{array}$ & $\begin{array}{c}\text { Progression of disease } \\
\text { state }\end{array}$ \\
\hline 1 & 38 & Penoscrotal vaginoplasty & 10 & No & No & No (CD4 count $\geq 500$ cells/uL) \\
2 & 50 & Vaginoplasty by FTSG & 7 & No & No & No (CD4 count $\geq 500$ cells/uL) \\
\hline FTSG, full thickness skin graft. & & & & & \\
\hline
\end{tabular}

Fig. 2. Case 2: Vaginoplasty by FTSG

(A) Preoperative image: Vaginoplasty was performed, but the vaginal stenosis was severe. (B) Image 10 months postoperatively: The skin of the adhered vagina was incised and expanded to perform full-thickness grafting. (C) Inner image of the reconstructed vagina seven months after the surgery: loss of the grafted skin was still observed, but had recovered well. The width and the orifice of the vagina had persisted. FTSG, full thickness skin graft.

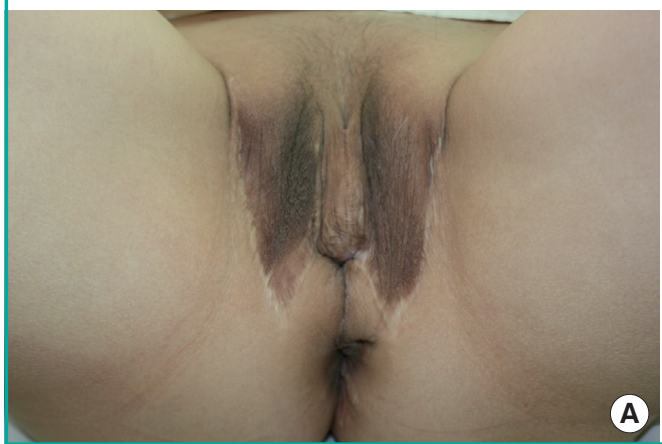

cells/ $\mu \mathrm{L}$, which was a 500 or higher CD4 T-cell count (Stage 1). In the PCR test on the blood, the HIV RNA was 'undetectable, so the surgery was performed. The skin of the adhered vagina was dissected and expanded. The expanded defect area was then covered by a full-thickness skin graft. A memory foam sponge was inserted into the reconstructed vagina to prevent adhesion recurrence, and the expanded vagina was maintained. No wound infection developed after the surgery. The skin was

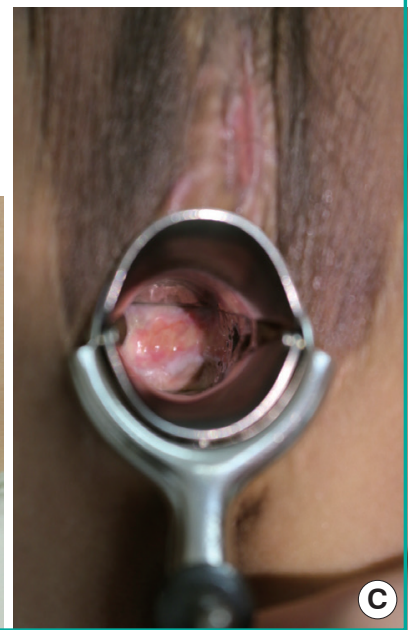

(C) 


\section{DISCUSSION}

The HIV is known as a lentivirus (slowly replicating retrovirus), and can be transmitted through the blood, semen, vaginal fluid, pre-ejaculate, breast milk, and other bodily fluids. When helper $\mathrm{T}$ cells (specifically $\mathrm{CD} 4^{+} \mathrm{T}$ cells), which are the major cells of the human immune system, are infected with HIV, the number of $\mathrm{CD}^{+} \mathrm{T}$ cells decreases and the cell-mediated immunity is destroyed. Consequently, the risk of opportunistic infection increases. In addition, when macrophage and dendritic cells are infected with HIV, immune function disorders may develop. With the progress of the disease, HIV-infected patients may eventually experience an immunocompromised condition, the AIDS, including symptoms such as frequent infections, tumor development, neurologic disorders, and complications that include lipodystrophy due to the continuous use of antiviral agents [6].

Surgical treatment of HIV-positive patients has not been actively performed due to concerns over infection after the surgery from the lowered immune functions of the patient, delayed wound healing caused by a slow inflammatory response, contamination of surgical appliances and equipment, and concerns about accidental transmission during surgery [7]. However, the mortality rate from HIV infection has been consistently decreasing due to the development of HAART, and more and more HIV patients are surviving longer than before. Accordingly, the frequency of AIDS-associated complications is increasing. The number of HIV-positive patients who want plastic surgical corrections for lipodystrophy symptoms, which are the complications of unwanted fat accumulations in the neck and facial areas caused by the long-term use of antiviral agents, is also increasing. In particular, HIV-positive patients are not unusual in the gender reassignment surgery field. Therefore, it is necessary to clearly understand the measures needed for safe surgery and for the prevention of viral transmission during surgery.

According to the HIV classification system prepared by the World Health Organization, HIV diseases have four stages, according to the CD4+ T cell count. In Stage I, the symptoms are subclinical, and the CD4+ T cell count is $>500$ cells $/ \mu \mathrm{L}$. In Stage II, mild symptoms such as mucocutaneous manifestations and recurrent upper respiratory infections appear, and the CD4+ T cell count is $<500$ cells $/ \mu \mathrm{L}$. In Stage III, advanced symptoms of severe infection such as persistent diarrhea without a clear etiology that lasts longer than a month, and tuberculosis, appear, and the CD4+ T cell count is $<350$ cells $/ \mu \mathrm{L}$. Finally, in Stage IV, which is already a type of AIDS, severe symptoms such as cerebral toxoplasmosis; candidiasis in the esophagus, trachea, or bronchi; and Kaposi's sarcoma develop, and the $\mathrm{CD} 4+\mathrm{T}$ cell count is $<200$ cells $/ \mu \mathrm{L}$ (Table 3 ).
Table 3. Classification system for HIV (World Health

Organization)

\begin{tabular}{|lll|}
\hline Stage & $\begin{array}{c}\text { CD4 T } \\
\text { cell } \\
\text { count } \\
\text { (cells/uL) }\end{array}$ \\
\hline $\begin{array}{lll}\text { Primary HIV } \\
\text { infection }\end{array}$ & $>500$ & $\begin{array}{l}\text { Asymptomatic or } \\
\text { Acute retroviral syndrome }\end{array}$ \\
\hline I & $>500$ & $\begin{array}{l}\text { Asymptomatic } \\
\text { Generalized lymph node enlargement }\end{array}$ \\
III & $<500$ & $\begin{array}{l}\text { Mucocutaneous manifestations } \\
\text { Recurrent URI }\end{array}$ \\
IV (AIDS) & $<350$ & $\begin{array}{l}\text { Advanced symptoms } \\
\text { Unexplained chronic diarrhea for longer than a month } \\
\text { Severe bacterial infections including Tb of the lung }\end{array}$ \\
& & $\begin{array}{l}\text { Severe symptoms } \\
\text { Toxoplasmosis of the brain } \\
\text { Candidiasis of the esophagus, trachea, bronchi, or lungs } \\
\text { Kaposi's sarcoma }\end{array}$ \\
\hline HIV, human immunodeficiency virus; AlDS, acquired immune deficiency syn- \\
drome.
\end{tabular}

The normal CD4+ T cell count is 500-1,500 cells $/ \mathrm{mm}^{3}$. Based on the cell count, the stage of the HIV infection, the initiation of ART treatment, and prophylactic treatments for opportunistic infection are determined. Therefore, the CD4+ $\mathrm{T}$ cell count is an important test that must be conducted in the early stage of the disease. For example, if the number of the CD4+ T lymphocytes is less than $350 / \mathrm{mm}^{3}$, ART must be implemented; if it is less than $200 / \mathrm{mm}^{3}$, prophylactic antibiotics for Pneumocystis jirovecii pneumonia must be administered, and prophylactic therapy for Mycobacterium avium complex infection is required.

In HIV patients, the bacterial infection rate has been understood to increase, and the wound healing ability to decrease, due to blunted inflammatory responses [7]. However, in recent studies, when the blood HIV level was suppressed due to HAART and when the CD4+ T cell count increased, the patient's immune function, which had been lost due to the low CD4+ T cell count, recovered, and what is known as the immune recovery syndrome' developed. When the immune function had recovered, HIV complications were reported to have been prevented and the patient's life span was extended with improved quality of life [4].

In our cases, before the sex reassignment surgery for HIV-positive patients, six-month HAART treatments were conducted, and the surgery was performed only on the Stage I patients whose preoperative CD4+ T cell count was $500 / \mathrm{mm}^{3}$ or more and whose blood HIV level was 'undetectable.' When the CD4+ $\mathrm{T}$ cell count is more than $500 / \mathrm{mm}^{3}$, the risks of infection and opportunistic infection do not differ significantly from those of HIV-negative patients, and the patient's immune function is 
known to be maintained. When the blood HIV RNA level is 'undetectable,' occupational exposure is very unlikely to result in HIV transmission to the surgical team. When the medical team receives appropriate after-exposure PEP, the possibility of HIV transmission may decrease further [7-10].

A prophylactic first-generation cephalosporin antibiotic (1 g cefazolin IV) was administered to the subject patients after the operation to prevent infection. A thorough skin preparation was conducted before the surgery, and disposable waterproof tissues were used. As a result, the patients did not experience specific complications such as wound infection and delayed wound healing in wound recovery up to seven and 10 months postoperatively, and in each case, the vagina was successfully reconstructed. Following the results of the previous study on the decrease in the HIV transmission risk with the use of protectors during the surgery by the surgical team, the entire surgical team in this study wore protective glasses, protective clothes, and three pairs of surgical gloves. As a result, the surgical team was not exposed. However, we had a plan in case of exposure during surgery. In case of such exposure, initial PEP would have been conducted within two hours, following the 2012 guidelines of the New York State Department of Health AIDS Institute for preventing occupational HIV after exposure. PEP, which involved the 28-day use of TDF, FTC, and raltegravir, also would have been conducted [7-9].

Several clinical studies have demonstrated that HIV transmission can be significantly reduced by the post-exposure administration of anti-retroviral agents. A dramatic decline in vertical transmission was observed in the AIDS Clinical Trial Group 076 study in which pregnant women and their newborns received monotherapy with zidovudine (ZDV) [11]. A CDC retrospective case control study of the use of ZDV after occupational HIV exposure in health-care workers showed an $81 \%$ reduction in the risk of HIV infection in those who had received ZDV [12].

The ultimate goals of PEP are to maximally suppress any limited viral replication that may occur and to shift the biological advantage to the host's cellular immune system in order to prevent or abort early infection; therefore, The Medical Care Criteria Committee recommends the use of a three-drug PEP regimen for any significant risk exposure.

In accordance with the guidelines, occupational PEP should

\section{Fig. 3. Post-exposure prophylaxis following occupational exposure}

PEP, post-exposure prophylaxis; HIV, human immunodeficiency virus; PO, per oral; qd, quaque die.

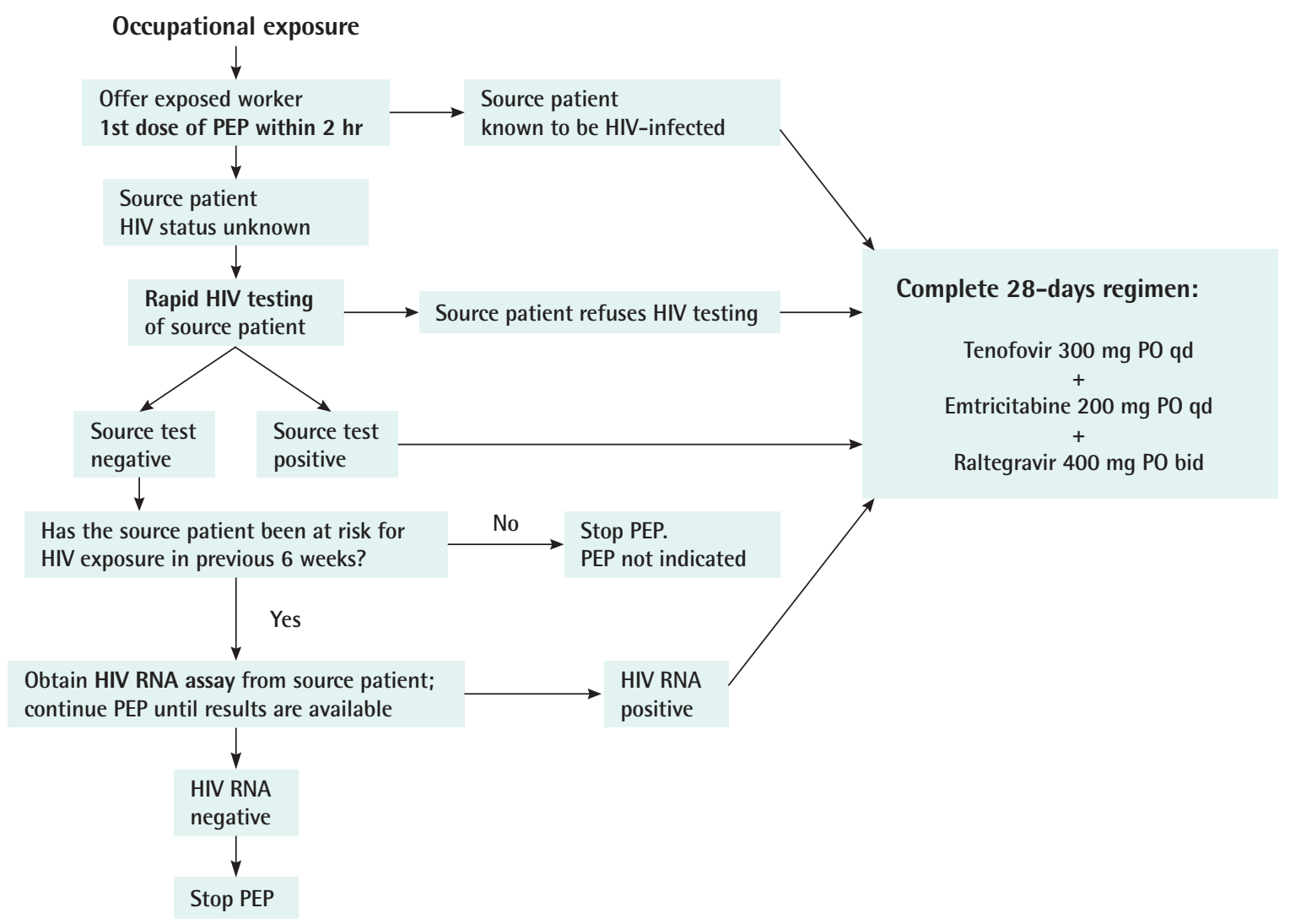


be initiated as soon as possible, ideally within 2 hours of exposure in the case of a source patient known from the patient's medical record to be HIV-infected. In the case of a source patient's HIV status being unknown, the first dose of PEP should be offered to the exposed worker while evaluation, such as rapid HIV testing of the source patient, is underway. If the test result is positive or the source patient refuses HIV testing, a complete 28-day regimen of TDF, FTC, and raltegravir is to be prescribed for the healthcare worker. If the test result is negative, the source patient's risk to HIV exposure during the prior 6 weeks (window period) should be evaluated. If there was no risk of HIV exposure during the prior 6 weeks and the test results of the source patient are negative, PEP is not indicated and can be discontinued. If there was any risk of HIV exposure in the prior 6 weeks, a HIV RNA assay of the source patient should be conducted, even if the rapid HIV testing result is negative. If the HIV RNA assay test result is positive, a complete 28 -day regimen is to be prescribed for the healthcare worker. If the HIV RNA assay test result is negative, the PEP regimen can be discontinued (Fig. 3).

According to the New York State Department of Health AIDS Institute, the mean risk of transmission following HIV positive patients' blood transfusion is roughly 9,000 in 10,000 (90\%). But in case of percutaneous exposure, the mean risk of transmission is only 30 in $10,000(0.3 \%)$. Furthermore, as we noted above, the probability of HIV transmission may further decrease (by $81 \%$ ) when appropriate after-exposure PEP is conducted. Therefore, early PEP within two hours after exposure is required $[13,14]$.

According to the guidelines of the New York State Department of Health AIDS Institute, the routine test that was previously conducted every six months after exposure is no longer recommended. Instead, the HIV test is recommended four and 12 weeks after the exposure. If the result of the test 12 weeks after the exposure is negative, the possibility of HIV infection can be excluded.

As described in our cases, we recommended appropriate preoperative HAART treatments to help the patient's immune functions to recover to the Stage I level. In addition, the administration of appropriate prophylactic antibiotics before the surgery, and thorough skin preparation, can minimize the development of complications after the surgery. The use of protectors by the surgical team can prevent occupational exposure, and the use of appropriate PEP regimens in case of exposure may significantly decrease the HIV transmission risk and enhance the safety of the surgery.

\section{REFERENCES}

1. Attia S, Egger M, Muller M, et al. Sexual transmission of HIV according to viral load and antiretroviral therapy: systematic review and meta-analysis. Aids 2009;23:1397-404.

2. Palella FJ Jr, Delaney KM, Moorman AC, et al. Declining morbidity and mortality among patients with advanced human immunodeficiency virus infection. HIV Outpatient Study Investigators. N Engl J Med 1998;338:853-60.

3. Lane HC, Masur H, Edgar LC, et al. Abnormalities of B-cell activation and immunoregulation in patients with the acquired immunodeficiency syndrome. N Engl J Med 1983; 309:453-8.

4. Leone S, Gregis G, Quinzan G, et al. Causes of death and risk factors among HIV-infected persons in the HAART era: analysis of a large urban cohort. Infection 2011;39:13-20.

5. Shelburne SA, Visnegarwala F, Darcourt J, et al. Incidence and risk factors for immune reconstitution inflammatory syndrome during highly active antiretroviral therapy. AIDS 2005;19:399-406.

6. Schnittman SM, Greenhouse JJ, Psallidopoulos MC, et al. Increasing viral burden in $\mathrm{CD} 4+\mathrm{T}$ cells from patients with human immunodeficiency virus (HIV) infection reflects rapidly progressive immunosuppression and clinical disease. Ann Intern Med 1990;113:438-43.

7. Seltzer DG, McAuliffe J, Campbell DR, et al. AIDS in the hand patient: the team approach. Hand Clin 1991;7:433-45.

8. Modjarrad K, Chamot E, Vermund SH. Impact of small reductions in plasma HIV RNA levels on the risk of heterosexual transmission and disease progression. AIDS (London, England) 2008;22:2179-85.

9. Mayer KH, Mimiaga MJ, Gelman M, et al. Raltegravir, tenofovir $\mathrm{DF}$, and emtricitabine for postexposure prophylaxis to prevent the sexual transmission of HIV: safety, tolerability, and adherence.J Acquir Immune Defic Syndr 2012;59:354-9.

10. Henderson DK, Fahey BJ, Willy M, et al. Risk for occupational transmission of human immunodeficiency virus type 1 (HIV-1) associated with clinical exposures: a prospective evaluation. Ann Intern Med 1990;113:740-6.

11. Connor EM, Sperling RS, Gelber R, et al. Reduction of maternal-infant transmission of human immunodeficiency virus type 1 with zidovudine treatment: Pediatric AIDS Clinical Trials Group Protocol 076 Study Group. N Engl J Med 1994; 331:1173-80.

12. Cardo DM, Culver DH, Ciesielski CA, et al. A case-control study of HIV seroconversion in health care workers after percutaneous exposure: Centers for Disease Control and Prevention Needlestick Surveillance Group. N Engl J Med 1997; 
337:1485-90.

13. Otten RA, Smith DK, Adams DR, et al. Efficacy of postexposure prophylaxis after intravaginal exposure of pig-tailed macaques to a human-derived retrovirus (human immunodeficiency virus type 2). J Virol 2000;74:9771-5.
14. Panlilio AL, Cardo DM, Grohskopf LA, et al. Updated U.S. Public Health Service guidelines for the management of occupational exposures to HIV and recommendations for postexposure prophylaxis. MMWR Recomm Rep 2005;54:1-17. 